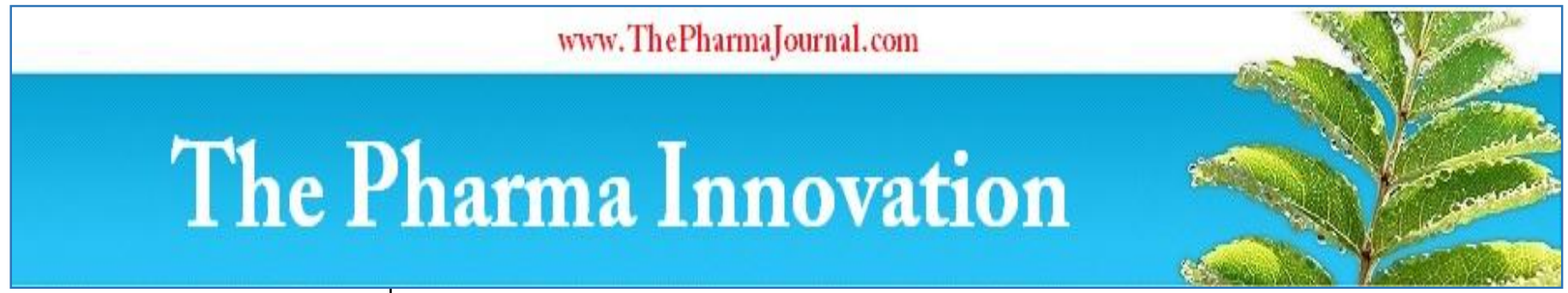

ISSN (E): 2277 - 7695

ISSN (P): 2349-8242

NAAS Rating: $\mathbf{5 . 0 3}$

TPI 2020; 9(11): 241-246

(C) 2020 TPI

www.thepharmajournal.com

Received: 22-09-2020

Accepted: 24-10-2020

Rajesh Kumar

Ph.D., Scholar, Division of

Surgery, ICAR, Indian

Veterinary Institute, Izatnagar,

Bareilly, Uttar Pradesh, India

Aakanksha

P. G. Scholar, Division of

Surgery, ICAR, Indian

Veterinary Institute, Izatnagar,

Bareilly, Uttar Pradesh, India

\section{AK Das}

Ph.D Scholar, Division of

Medicine, ICAR, Indian

Veterinary Institute, Izatnagar,

Bareilly, Uttar Pradesh, India

NK Verma

Ph.D., Scholar, Division of

Surgery, ICAR, Indian

Veterinary Institute, Izatnagar,

Bareilly, Uttar Pradesh, India

\section{AC Saxena}

Scientist, Division of Surgery,

ICAR, Indian Veterinary

Institute, Izatnagar, Bareilly,

Uttar Pradesh, India

\section{Hoque}

Principal Scientist, Division of

Surgery, ICAR, Indian

Veterinary Institute, Izatnagar,

Bareilly, Uttar Pradesh, India

\section{Corresponding Author:}

Rajesh Kumar

Ph.D., Scholar, Division of

Surgery, ICAR, Indian

Veterinary Institute, Izatnagar,

Bareilly, Uttar Pradesh, India

\section{Systemic effects and clinical application of dexmedetomidine}

\author{
Rajesh Kumar, Aakanksha, AK Das, NK Verma, AC Saxena and M \\ Hoque
}

DOI: $\underline{\text { https://doi.org/10.22271/tpi.2020.v9.i11d.5344 }}$

\begin{abstract}
Dexmedetomidine is a most potent $\alpha-2$ adrenergic selective agonist. It is one of the components of the racemic mixture of two enantiomers of medetomidine. It has a selectivity ratio of $1620 / 1(\alpha 2 / \alpha 1)$, which is 5-10 times higher than that for detomidine (260/1) and xylazine (160/1. Dexmedetomidine produces consistent sedation, anxiolysis and muscle relaxation, which makes it a popular sedative agent in veterinary medicine. In veterinary practice, it is used for premedication and as an adjunct to general anaesthesia in several species. Similar to other alpha- 2 agonists it exerts its effect through the action on alpha- 2 adrenergic receptors. The sedative and anxiolytic effects of $\alpha-2$ agonists are mediated by agonism of supraspinal autoreceptors situated in the pons, whereas analgesic effects are mediated by agonism of heteroreceptors located in the dorsal horn of the spinal cord. Dexmedetomidine causes a dose-dependent redistribution of blood flow and preserves blood flow to the most vital organs at the expense of organs like skin and pancreases and this distribution of blood flow is not affected by the type of anaesthesia. The pattern of cardiovascular changes may be affected by the dose used and the type of anaesthetic combined with dexmedetomidine. Most anaesthetic drugs, such as propofol, thiopental, isoflurane and halothane have cardiovascular and respiratory side effects that are dose-dependent. Dexmedetomidine is a good anaesthetic adjuvant for general anaesthesia which reduces intra-operative isoflurane consumption provides analgesic-sparing effect without affecting postoperative recovery profile and improved cardiovascular stability and contributes to the provision of balanced anaesthesia.
\end{abstract}

Keywords: Dexmedetomidine, $\alpha-2$ agonists, sedation, respiratory effect and cardiovascular effect

\section{Introduction}

The ideal sedative or premedication regimen would provide reliable sedation, anxiolysis, muscle relaxation and analgesia, while the influence on the haemodynamic and pulmonary function would be minimal. In addition, it would be reversible. Alpha-2 adrenoceptor agonists agents are extensively used in veterinary anaesthesiology since the late sixties with the advent of xylazine and use in cattle and horses (Clarke and Hall, 1969) ${ }^{[17]}$. Currently, $\alpha-2$ adrenoceptor agonists are used in domestic and several wild species due to their effects on centrally located $\alpha-2$ adrenoceptors causing sedation and analgesia. Newer drugs such as romifidine, detomidine and medetomidine with a higher selectively towards $\alpha-2$ adrenoceptor were developed and introduced in veterinary practice. Currently, the newest and most selective $\alpha-2$ adrenoceptors agonist drug used in small animals is dexmedetomidine (Seddighi, 2014) [49]. However, similar to other $\alpha-2$ adrenoceptor agonists, dexmedetomidine is associated with marked adverse effects of the cardiovascular system, which make unsuitable for administration in younger than 6 months or patient with cardiovascular disease (Ko et al., 2009) [26]. Dexmedetomidine causes biphasic changes in arterial blood pressure (ABP) (Bloor et al., 1992) ${ }^{[12]}$. Activation of peripheral $\alpha-2$ adrenoceptors in vascular smooth muscle leads to vasoconstriction and increases systemic vascular resistance (SVR) which causes arterial hypertension and reflex bradycardia (Bloor et al., 1992 and Pypendop and Verstegen, 1998) ${ }^{[12,42]}$. Activation of $\alpha-2$ adrenoceptors in the brain causes sedation and analgesia as well as a decrease in sympathetic outflow in conjunction with augmentation of parasympathetic tone, those results in centrally mediated bradycardia followed by a decrease in arterial blood pressure (ABP) (Ruffolo et al., 1993 and MacMillan et al., 1996) ${ }^{[46,36]}$. In small animal practice, anaesthesia is commonly maintained with an inhalant anaesthetic such as isoflurane or sevoflurane. Isoflurane effects hemodynamic homeostasis by decreasing SVR and depressing myocardial function (Brahim and Thut, 1984 and Mutoh et al., 1997) ${ }^{[13,38]}$. Thus, hypotension is a common problem associated with the administration of inhalant anaesthetics. 
Dexmedetomidine decreases vasodilatation and the subsequent reduction in MAP in isoflurane-anesthetized dogs (Ohata et al., 1999) [40]. Dexmedetomidine is a good anaesthetic adjuvant for general anaesthesia which reduces intra-operative isoflurane consumption, provides analgesicsparing effect without affecting postoperative recovery profile (Reshma et al., 2016) ${ }^{[44]}$.

\section{Mechanism of action}

Alpha-2 agonists exert their effects through the action on alpha-2 adrenergic receptors. Alpha-2 receptors are located pre-synaptically and post-synaptically in neuronal as well as non-neuronal tissues and extrasynaptically in the vasculature. Alpha-2 receptors present on noradrenergic neurons are called "autoreceptors" and those on nonnoradrenergic neurons are called "heteroreceptors" (Burton, 1997) ${ }^{[14]}$. The sedative and anxiolytic effects of alpha-2 agonists are mediated by agonism of supraspinal-autoreceptors situated in the pons (Locus coeruleus), whereas analgesic effects are mediated by agonism of heteroreceptors located in the dorsal horn of the spinal cord (Burton, 1997) ${ }^{[14]}$.

The mechanism of action of dexmedetmidine is uniques and differs from others those currently used as sedative agents, including clonidine. Activation of the receptors in the brain and spinal cord inhibits neuronal firing, causing hypotension, bradycardia, sedation, and analgesia. The responses to activation of the receptors in other areas include decreased salivation, decreased secretion and decreased intestinal motility in the gastrointestinal tract. It also decreased contraction of vascular and other smooth muscle, inhibition of renin release, increased glomerular filtration and increased secretion of sodium and water in the kidney, decreased intraocular pressure and decreased insulin release from the pancreas (Merz et al., 1978) ${ }^{[37]}$.

In the rat, dexmedetomidine has been shown to bind to $\alpha-2 \mathrm{~A}$ adrenoreceptors on the cell membrane of neurons of locus coeruleus and leads to the opening of inward rectifying potassium channels, resulting in hyperpolarization of the membrane (Chiu et al., 1995) ${ }^{[16]}$. The neuronal hyperpolarization may be a key element in the mechanism of action of $\alpha-2$ adrenoreceptor agonists from the viewpoint of an anaesthesiologist (Birnbaumer et al., 1990) ${ }^{[10]}$.

\section{Sedative effects}

The sedative effects of dexmedetomidine are mediated supraspinally, predominantly via activity within the locus coeruleus of the brainstem, while antinociceptive effects result mainly from activity within the spinal cord at both pre and post-synaptic locations within the dorsal horn. Dexmedetomidine absorbed rapidly resulting in a faster onset of sedation and analgesia. In dog's sedation scores and analgesic effect following dexmedetomidine (10 and $20 \mu \mathrm{g} / \mathrm{kg}$ IV) and medetomidine (40 $\mu \mathrm{g} / \mathrm{kg}$ IV) did not differ significantly with each other during the first hour after administration. Whereas, from 90 minutes onwards, animals receiving the higher dose of dexmedetomidine had greater sedation scores and analgesic effects when compared to medetomidine.

Dexmedetomidine at the dose rate of $5 \mathrm{mcg} / \mathrm{kg}$ intravenously produces moderate to profound sedation, that lasting to up to 30 minutes in canines. The combination of dexmedetomidine and acepromazine $(0.05 \mathrm{mg} / \mathrm{kg})$ does not modify the intensity the sedative effect nor prolongs sedative effects of dexmedetomidine. Profoundly sedated animals will remain spontaneously in lateral recumbency. The mouth can be opened and the tongue may be manually exposed without difficulty (Alvaides et al., 2008) ${ }^{[5]}$. In dogs, it appears that a ceiling sedative effect is achieved with a dose of $10 \mathrm{mcg} / \mathrm{kg}$. By increasing the intravenous dose of dexmedetomidine from 10 to $20 \mathrm{mcg} / \mathrm{kg}$ can increases the duration but not the intensity of sedation (Kuusela et al., 2000) ${ }^{[28]}$.

\section{Analgesic effects}

In comparison to sedative action, alpha- 2 agonist, induced analgesia is relatively shorter period (Kuusela et al., 2000) ${ }^{[28]}$. Analgesic effects of dexmedetomidine ( $20 \mathrm{mcg} / \mathrm{kg} / \mathrm{IV})$ longer than the analgesic effects produced by an equipotent dose of medetomidine (40 mcg/kg/IV) (Kuusela et al., 2000) ${ }^{[28] .}$ Dexmedetomidine has both spinal and supraspinal analgesic actions. There was very close association between opioid and a2-adrenergic receptors (Unnerstall et al., 1984) and the enhanced antinoceptive actions occur following simultaneous administration of agonists at these sites in the spinal cord (Omote et al., 1991). Lower doses of dexmedetomidine (5-10 $\mathrm{mcg} / \mathrm{kg}$ in dogs and $10-20 \mathrm{mcg} / \mathrm{kg}$ in cats) have been combined with opioid analgesics with the expectation of achieving a synergistic analgesic effect. In cats only the highest dose of dexmedetomidine (40 mcg/ $/ \mathrm{kg}$ ) showed antinociceptive effects to a thermal stimulus applied to the skin (Slingsby and Taylor, 2008) ${ }^{[51]}$. The dose required to produce analgesia in cats $(40 \mathrm{mcg} / \mathrm{kg})$ is relatively high, that can produce a potential unwanted side effects like excessive cardiopulmonary depression.

\section{Hypothermia}

Alpha 2-agonists cause dose-dependent hypothermia (MacDonald et al., 1988) [35] due to depression of noradrenergic receptors in the hypothalamus. A slight decrease in rectal temperature was observed in dogs sedated with dexmedetomidine.

\section{Effect of dexmedetomidine on the different systems on the animal. \\ Respiratory effect}

Both medetomidine and dexmedetomidine reduce the respiratory rate (Lerche and Muir 2004 and Acevedo-Arcique et al., 2014) [32, 1]. Cyanosis reported up to $33 \%$ in $\operatorname{dogs}$ sedated with medetomidine (Hellebrekers, 1993) ${ }^{[23]}$. Cyanotic animals show insignificant changes to arterial blood oxygen tension and oxygen saturation more than 95\%, however, oxygen tension remains low and venous filling is slow. In addition, after the systemic administration of medetomidine or dexmedetomidine, a response to the increased carbon dioxide tension was decreased in consciousness (Sabbe et al., 1994) [47] and anaesthetised dogs (Lerche and Muir, 2006) ${ }^{[33]}$. However, they induce minimal effects on arterial oxygen or carbon dioxide partial pressures when administered alone to conscious dogs (Sabbe et al., 1994 and Pypendop and Verstegen, 1998) ${ }^{[47,42]}$. The higher doses of dexmedetomidine induce mild metabolic acidosis accompanied by a compensatory increase in arterial bicarbonate concentration (Kuusela et al., 2001) ${ }^{[29]}$. Bettschart-Wolfensberger, (2005) ${ }^{[9]}$ reported a decrease in respiratory rate throughout the $60 \mathrm{~min}$. the observation period, but no change in arterial $\mathrm{PaO} 2$ or $\mathrm{PaCO} 2$ when dexmedetomidine was administered intravenously in ponies. A transitory decrease in respiratory rate was observed after a single administration of dexmedetomidine in cats (Ansah et al., 1998 and Selmi et al., 
2003) [6, 50]. Concurrent administration of dexmedetomidine with butorphanol, midazolam, fentanyl and ketamine resulted in a significant decrease in the respiratory rate in both dogs and cats (Ahmad et al., 2013 and Santosh et al., 2013) ${ }^{[2,4,48] .}$ Isoflurane anaesthesia in dogs caused more respiratory depression alone, in compare along with medetomidine or dexmedetomidine (Bloor et al., 1989 and Nguyen et al., 1992) $[11,39]$. It is due to a decreased requirement of isoflurane to maintain anaesthesia.

\section{Cardiovascular effect}

Dexmedetomidine, similarly to other $\alpha-2$ adrenoceptor agonists, has marked cardiovascular effects that are mediated by peripheral (Flacke et al., 1990) ${ }^{[20]}$ and central receptors (Link et al., 1996 and MacMillan et al., 1996) [34, 36]. Typically, after a bolus, initial vasoconstriction and increase in SVR occurs, leading to a transient elevation of ABP and CVP and a reduction of HR (Bloor et al., 1992 and Flacke et al., 1993) ${ }^{[12,21]}$. It causes a decrease in cardiac output as much as $70 \%$ despite persistently elevated blood pressure. The cardiac output reduction affects the blood flow differently among the different organs (Talke et al., 2000 and Pypendop and Verstegen, 2000) ${ }^{[52,43]}$. After the administration of dexor medetomidine, a dose-dependent redistribution of blood flow occurs. Dexmedetomidine preserves blood flow to the most vital organs like brain, heart, liver and kidney, at the expense of organs like skin and pancreases and this distribution of blood flow is not affected by the type of

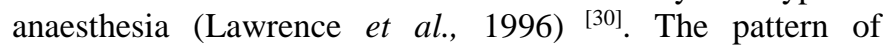
cardiovascular changes may be affected by the dose used and the type of anaesthetic combined with dexmedetomidine. A direct negative inotropic effect of dexmedetomidine on the myocardium is unlikely to occur (Housmans, 1990 and Flacke et al., 1992) ${ }^{[24,22]}$. Coronary blood flow is reduced with doses higher than $1 \mu \mathrm{g} / \mathrm{kg}$, while the coronary vascular resistance is increased (Flacke et al., 1993) ${ }^{[21]}$. In addition, increases in systemic and myocardial oxygen concentrations are indicative of hypoxemia (Flacke et al., 1993) ${ }^{[21]}$. Roekaerts et al. (1996) [45] described nun significant changes in the oxygen and lactate concentration despite an increased myocardium vascular resistance and reduce blood flow. These results are similar to those reported by Jalonen et al. (1995) ${ }^{[25]}$, who observed no signs of myocardium ischemia in dexmedetomidine-treated pigs. Intracoronary infusion of dexmedetomidine was associated with a reduction of reperfusion-induced arrhythmias in the same species (Yoshitomi et al., 2012) ${ }^{[55]}$.

\section{Endocrine effect}

Various studies have reported that $\alpha 2$-agonists reduce the release of perioperative levels of stress-related hormones and thus attenuate the stress response of surgery in canines (Benson et al., 2000) ${ }^{[8]}$. In human anaesthesia and surgery, the stress response of surgery is an important factor contributing to patient morbidity, so, pre-anaesthetics like a $\alpha 2$-agonist can be used to minimize this response (Desborough, 2000) ${ }^{[19]}$.

\section{Gastro-intestinal effect}

Alpha-2 agonists decrease the salivation, gastric secretion, gastro-esophageal sphincter pressure, esophageal, gastric and small intestinal motility. Vomiting causes by another $\alpha 2-$ adrenoceptor agonist like xylazine in cats is due to stimulation of receptors in the chemoreceptor trigger zone in the brain
(Colby et al., 1981). Similar effect could have been observed with dexmedetomidine.They may promote ulcer formation. Alph-2 induces vomiting in $8-20 \%$ of canines and up to 90 $100 \%$ of felines (pypendop, 2005) ${ }^{[41]}$. Development of aspiration pneumonia may occur with dexmedetomidine, if a properly inflated cuffed endotracheal tube is not in place. Administration of anticholinergic agents 10 to $20 \mathrm{~min}$ before administration of alpha- 2 agonists, reduce the occurrence of vomiting in canines (Lemke, 2001) [31]. In general, $\alpha 2$ adrenergic agonists decrease acid gastric and salivary secretions and prolong intestinal transit time. It decreases the motility of the colon dramatically in canines (Asai et al., 1998) ${ }^{[7]}$. Dexmedetomidine inhibits gastric emptying and gastrointestinal transit in rats (Asai et al., 1998) ${ }^{[7]}$. Inhibitory effect of morphine on gastrointestinal transit is markedly enhanced by dexmedetomidine, but it did not have significantly effect on gastric emptying.

\section{Clinical use}

Dexmedetomidine generally combined with butorphanol for premedication prior to induction of general anaesthesia using propofol. Most anaesthetic drugs, such as propofol, thiopental, isoflurane and halothane have cardiovascular and respiratory side effects that are dose-dependent. Therefore, a reduction in the dose of these agents can lead to improved cardiovascular stability and contributes to the provision of balanced anaesthesia. Kuusela et al. (2001) ${ }^{[29]}$ studied various premedicant doses of dexmedetomidine administrated intravenously in canines under propofol and isoflurane anaesthesia and found that dose level up to $20 \mu \mathrm{g} / \mathrm{kg}$ preserved blood pressure but profound bradycardia occurred at the dose $20 \mu \mathrm{g} / \mathrm{kg}$. The dose level of $2 \mu \mathrm{g} / \mathrm{kg}$ resulted in more stable cardiovascular effects but the effect was short period and a stable plane of anaesthesia was difficult to maintain. Dexmedetomidine also decreases the minimum alveolar concentration (MAC) of inhalant anaesthetic for maintaining anaesthesia in a dose-related fashion. In dogs, isoflurane MAC was reduced by $89 \%$ after 30 minutes of dexmedetomidine administration $(20 \mu \mathrm{g} / \mathrm{kg} / \mathrm{IV})$ (Bloor et al., $1992)^{[12]}$. In dogs receiving dexmedetomidine $(5-10 \mu \mathrm{g} / \mathrm{kg})$ combined with opioids, the requirements of injectable agents for allowing orotracheal intubation may be markedly decreased. In this case, doses of propofol as low as 0.5 to 1 $\mathrm{mg} / \mathrm{kg}$ may be enough for placing the orotracheal tube. The administration of inhalant anaesthetic agent during the early phase of maintenance of anaesthesia ( 30 minutes) becomes less than $0.5 \%$.

Epidural administration of dexmedetomidine in dogs results in a prolonged analgesic effect, with the use of lower doses than those used by intravenous administration (Sabbe et al., 1994) ${ }^{[47]}$. Dexmedetomidine at the dose rate of 3.0 and 6.0 $\mathrm{mcg} / \mathrm{kg}$ epidurally in canine caused clinically significant decreases in isoflurane MAC (defined as a reduction in MAC above $20 \%$ ) for approximately 2 and 4.5 hours, respectively (Campagnol et al., 2007) ${ }^{[15]}$. Continuous rate infusion (CRI) of dexmedetomidine in healthy dogs is being recommended as an adjunct to general anaesthesia as it reduces the dosage of general anaesthesia, provides a stable plane of anaesthesia and additional analgesia (Uilenreef et al., 2008 and Valtolina et al., 2009 Congdon et al., 2013) ${ }^{[53,54,18]}$. Dexmedetomidine can be used along with diazepam, midazolam, butorphanol, buprenorphine, fentanyl and ketamine, these combinations have been found both effective and safe in healthy dogs (Ahmad et al., 2011 Ahmad et al., 2013 and Santosh et al., 
2013) $[3,2,4,48]$. Dexmedetomidine is also very effective for intra-articular use. Like opioid, alpha-2 adrenoreceptors are distributed throughout the peripheral nervous system. By inhibiting the release of norepinephrine locally, they reduce noxious input and minimize the development of peripheral sensitization. Intraarticular used of dexmedetomidine (1-2.5 $\mu \mathrm{g} / \mathrm{kg})$ with morphine $(0.1 \mathrm{mg} / \mathrm{kg})$ and bupivacaine $(0.5-1.0$ $\mathrm{mg} / \mathrm{kg}$ ) provide long-lasting analgesia for arthrotomy.

Dexmedetomidine can provide postoperative analgesia from 0.5 to 4 hours. However, this duration of analgesia is dependents on a number of others factors. Due to the pronounced cardiovascular effects, dexmedetomidine should only used in clinically healthy dogs and cats (ASA classes I and II). Animals should be frequently monitored for cardiovascular function and body temperature during sedation or anaesthesia. Dexmedetomidine should not be used in patients with pre-existing hypotension, hypoxia or bradycardia. Apnea may occur with dexmedetomidine, therefore in the event of apnea, additional oxygen should be supplied.

\section{Implications and recommendations}

The ideal sedative or preanaesthetic agents provide reliable anxiolysis, muscle relaxation, sedation and analgesia with minimal and reversible effects on the hemodynamic and pulmonary function (Kumar et al., 2020) [27]. Dexmedetomidine is a very specific alpha-2 agonist, exerts well-defined effects on different body systems. It preserves the cardiovascular function better than any other alpha-2 agonists, in spite of being more potent. In veterinary practice, it is being used mainly in small animals like dogs and cats. Extensive studies are needed in the future to elucidate its application as clinical anesthesia for ruminants, since ruminants are very sensitive to common alpha-2 agonists like xylazine. It should also be evaluated as an adjunct to different anesthetics and analgesics for general and epidural anesthesia and pain management in bovine and equine species. Being a very potent alpha- 2 agonist, dexmedetomidine can be studied, for sedation and capture of wild animal species.

\section{Conclusion}

Dexmedetomidine is most potent $\alpha-2$ adrenergic selective agonist. It produces consistent sedation, anxiolysis and muscle relaxation, which makes it most important sedative agent in veterinary medicine. Dexmedetomidine produces moderate to profound sedation, that lasting up to 30 minutes in canines. Dexmedetomidine preserves blood flow to the most vital organs like brain, heart, liver and kidney, at the expense of organs like skin and pancreases and this distribution of blood flow is not affected by the type of anaesthesia. Dexmedetomidine can be used along with diazepam, midazolam, butorphanol, buprenorphine, fentanyl and ketamine, these combinations have been found both effective and safe in healthy dogs. General anaesthesia like propofol, thiopental, isoflurane and halothane has cardiovascular and respiratory side effects that are dosedependent. Dexmedetomidine reduce dose of these agents and preserve cardiovascular and respiratory function.

\section{References}

1. Acevedo-Arcique CM, Ibancovichi JA, Chavez JR, Gutierrez-Blanco E, Moran-Muñoz R, Victoria-Mora JM, et al. Lidocaine, dexmedetomidine and their combination reduce isoflurane minimum alveolar concentration in dogs', PloS one 2014;9(9):106620.

2. Ahmad R.A., Amarpal, Kinjavdekar P, Aithal, H.P., Pawde AM, Kumar D. Potential use of dexmedetomidine for different levels of sedation, analgesia and anaesthesia in dogs', Veterinarni Medicina 2013;58(2):87-95.

3. Ahmad RA, Amarpal Kinjavdekar P, Aithal HP, Pawde AM, Kumar D. Effects of midazolam or midazolamfentanyl on sedation and analgesia produced by intramuscular dexmedetomidine in dogs', Asian Journal of Animal Sciences 2011;5(5):302-316.

4. Ahmad RA, Kinjavdekar P, Aithal HP, Pawde AM, Kumar D. Potential use of dexmedetomidine for different levels of sedation, analgesia and anaesthesia in dogs. Veterinarni Medicina 2013;58(2):87-95.

5. Alvaides RK, Neto FT, Aguiar AJDA, Campagnol D, Steagall PVM. Sedative and cardiorespiratory effects of acepromazine or atropine given before dexmedetomidine in dogs', Veterinary Record 2008;162(26):852-856.

6. Ansah OB, Raekallio M, Vainio O. Comparison of three doses of dexmedetomidine with medetomidine in cats following intramuscular administration', Journal of veterinary pharmacology and therapeutics 1998;21(5):380-387.

7. Asai T, Mapleson WW, Power I. Interactive effect of morphine and dexmedetomidine on gastric emptying and gastrointestinal transit in the rat', British Journal of Anaesthesia 1988;80:63-7

8. Benson GJ, Grubb TL, Neff-Davis C, Olson WA, Thurmon JC, Lindner DL, et al. Perioperative stress response in the dog: effect of pre-emptive administration of medetomidine', Veterinary Surgery 2000;29(1):85-91.

9. Bettschart-Wolfensberger R, Freeman SL, Bowen IM, Aliabadi FS, Weller $\mathrm{R}$, Huhtinen $\mathrm{M}$, et al. Cardiopulmonary effects and pharmacokinetics of iv dexmedetomidine in ponies, Equine veterinary journal 2005;37(1):60-64.

10. Birnbaumer L, Abramowitz J, Brown AM. Receptor effector coupling by G proteins', Biochemica et Biophysica Acta 1990;1031:163-224.

11. Bloor BC, Abdul-Rasool I, Temp J, Jenkins S, Valcke C, Ward DS, et al. The effects of medetomidine, an alpha 2adrenergic agonist, on ventilatory drive in the dog', Acta veterinaria Scandinavica. Supplementum 1989;85:65-70.

12. Bloor BC, Frankland MARIA, Alper GLENN, Raybould DAVID, Weitz JANICE, Shurtliff $\mathrm{M}$, et al. Hemodynamic and sedative effects of dexmedetomidine in dog', Journal of Pharmacology and Experimental Therapeutics 1992;263(2):690-697.

13. Brahim JS, Thut PD. Hemodynamic changes during isofl urane anesthesia, Anaesthesia Progress 1984;31:207-212.

14. Burton SA, Lemke KA, Ihle SL, Mackenzie AL. Effects of medetomidine on serum insulin and plasma glucose concentrations in clinically normal dogs', American Journal of Veterinary Research 1997;58:14401442.

15. Campagnol D, Teixeira Neto FJ, Giordano T, Ferreira TH, Monteiro ER. Effects of epidural administration of dexmedetomidine on the minimum alveolar concentration of isoflurane in dogs', American journal of veterinary research 2007;68(12):1308-1318.

16. Chiu TH, Chen MJ, Yang YR, Yang JJ, Tang FI. Action of dexmedetomidine on rat coerulus neurons: intracellularrecording in-vitro', European Journal of 
Pharmacology 1995;285:261-268.

17. Clarke KW, Hall LW. Xylazine"--a new sedative for horses and cattle', Veterinary Record 1969;85(19):512517.

18. Congdon JM, Marquez M, Niyom S, Boscan P. Cardiovascular, respiratory, electrolyte and acid-base balance during continuous dexmedetomidine infusion in anesthetized dogs', Veterinary Anaesthesia and Analgesia 2013;40(5):464-71.

19. Desborough JP. The stress response to trauma and surgery', British journal of anaesthesia 2000;85(1):109117.

20. Flacke JW, Flacke WE, Bloor BC, McIntee DF. Hemodynamic effects of dexmedetomidine, an alpha 2-adrenergic agonist, in autonomically denervated dogs', Journal of cardiovascular pharmacology 1990;16(4):616-623.

21. Flacke WE, Flacke JW, Bloor BC, McIntee DF, Sagan M. Effects of dexmedetomidine on systemic and coronary hemodynamics in the anesthetized dog', Journal of cardiothoracic and vascular anesthesia 1993;7(1):4149.

22. Flacke WE, Flacke JW, Blow KD, Mclntee DF, Bloor BC. Effect of dexmedetomidine, an $\alpha 2$-adrenergic agonist, in the isolated heart', Journal of cardiothoracic and vascular anesthesia 1992;6(4):418-423.

23. Hellebrekers LJ, Van Herpen H, Hird JFR, Rosenhagen CU, Sap R, Vainio O, et al. Clinical efficacy and safety of propofol or ketamine anaesthesia in dogs premedicated with medetomidine', Veterinary Record 1998;142(23):631-634.

24. Housmans PR. Effects of dexmedetomidine on contractility, relaxation, and intracellular calcium transients of isolated ventricular yocardium', Anesthesiology 1990;73(5):919-922.

25. Jalonen J, Halkola L, Kuttila K, Perttilä J, Rajalin A, Savunen $\mathrm{T}$, et al. Effects of dexmedetomidine on coronary hemodynamics and myocardial oxygen balance', Journal of cardiothoracic and vascular anesthesia 1995;9(5):519-524.

26. Ko JCH, Ann BW, Tomohito I. Effects of carprofen and morphine on the minimum alveolar concentration of isoflurane in dogs', Journal of the American Animal Hospital Association 2009;45(1):19-23.

27. Kumar R, Singh M, Verma NK, Akash R, Sasikala, Kumar R, et al. Systemic Effects and Clinical Application of Medetomidine in Animals', A Review. Indian journal of animal research 2020. DOI: $10.18805 /$ ijar.B-3864.

28. Kuusela E, Raekallio M, Anttila M, Falck I, Mölsä S, Vainio O, et al. Clinical effects and pharmacokinetics of medetomidine and its enantiomers in dogs', Journal of veterinary pharmacology and therapeutics 2000;23(1):1520.

29. Kuusela E, Raekallio M, Väisänen M, Mykkänen K, Ropponen $\mathrm{H}$, Vainio $\mathrm{O}$, et al. Comparison of medetomidine and dexmedetomidine as premedicants in dogs undergoing propofol-isoflurane anesthesia', American journal of veterinary research 2001;62(7):1073-1080.

30. Lawrence CJ, Prinzen FW, De Lange S. The effect of dexmedetomidine on nutrient organ blood flow', Anesthesia and Analgesia 1996;83(6):1160-1165.

31. Lemke KA. Electrocardiographic and cardiopulmonary effects of intramuscular administration of glycopyrrolate and romifidine in conscious beagle dogs, Veterinary Anesthesia and Analgesia 2001;28:7586.

32. Lerche P, Muir III WW. Effect of medetomidine on breathing and inspiratory neuromuscular drive in conscious dogs American journal of veterinary research 2004;65(6):720-724.

33. Lerche P, Muir III WW. Effect of medetomidine on respiration and minimum alveolar concentration in halothane-and isoflurane-anesthetized dogs, American journal of veterinary research 2006;67(5):782-789.

34. Link RE, Desai K, Hein L, Stevens ME, Chruscinski A, Bernstein $\mathrm{D}$, et al. Cardiovascular regulation in mice lacking $\alpha 2$-adrenergic receptor subtypes b and c', Science 1996;273(5276):803-805.

35. Mac Donald E, Scheinin H, Scheinin M. Behavioural and neurochemical effects of medetomidine, a novel veterinary sedative', European Journal of Pharmacology 1988;158:119-27.

36. MacMillan LB, Hein L, Smith MS, Piascik MT, Limbird LE. Central hypotensive effects of the $\alpha 2 \mathrm{~A}$-adrenergic receptor subtype, Science 1996;273(5276):801-803.

37. Metz SA, Halter JB, Robertson RP. Induction of defective insulin secretion and impaired glucose tolerance by clonidine, Selective stimulation of metabolic alpha-adrenergicpathways', Diabetes 1978;27:554-562.

38. Mutoh T, Nishimura R, Kim HY. Cardiopulmonary eff ects of sevofl urane, compared with halothane, enfl urane, and isofl urane, in dogs', American Journal of Veterinary Research 1997;58:885-890.

39. Nguyen D, Abdul-Rasool I, Ward D, Hsieh J, Kobayashi $\mathrm{D}$, Hadlock S, et al. Ventilatory effects of dexmedetomidine, atipamezole, and isoflurane in dogs', Anesthesiology 1992;76(4):573-579.

40. Ohata H, Iida H, Dohi S, Watanabe Y. Intravenous dexmedetomidine inhibits cerebrovascular dilation induced by isoflurane and sevoflurane in dogs', Anaesthesia and Analgesia 1999;89(2):370-377.

41. Pypendop B. In: $50^{\circ}$ Congresso Nazionale Multisala Scivac, - Rimini, Italia Alpha-2 adrenorecptor agonist in dogs and cats alpha 2 agonisti Nel Cane Enel Gatto 2005.

42. Pypendop BH, Verstegen JP. Hemodynamic effects of medetomidine in the dog: a dose titration study', Veterinary Surgery 1998;27(6):612-622.

43. Pypendop BH, Verstegen JP. Effects of a medetomidinemidazolam-butorphanol combination on renal cortical, intestinal and muscle microvascular blood flow in isoflurane anaesthetized dogs: a laser Doppler study', Veterinary anaesthesia and analgesia 2000;27(1):36-44.

44. Reshma BM, Geetha CR, Suresh G, Prathima PT. Effect of dexmedetomidine bolus dose on isoflurane consumption in surgical patients under general anesthesia', Anesthesia Essays Research 2016;10:649654.

45. Roekaerts PM, Prinzen FW, de Lange S. Coronary vascular effects of dexmedetomidine during reactive hyperemia in the anesthetized dog, Journal of cardiothoracic and vascular anesthesia 1996;10(5):619626.

46. Ruffolo Jr RR, Nichols AJ, Stadel JM, Hieble JP. Pharmacologic and therapeutic applications of alpha2adrenoceptor subtypes, Annual review of pharmacology and toxicology 1993;33(1):243-279. 
47. Sabbe MB, Penning JP, Ozaki GT, Yaksh TL. Spinal and systemic action of the alpha 2 receptor agonist dexmedetomidine in dogs, Antinociception and carbon dioxide response', Anesthesiology 1994;80(5):10571072.

48. Santosh KM, Amarpal Ahmad RA, Kinjavdekar P, Aithal HP, Pawde AM. Evaluation of midazolamketamine with dexmedetomidine and fentanyl for injectable anaesthesia in dogs', Veterinarski Arhiv 2013;83(5):509-523.

49. Seddighi R. A-2 adrenoceptor agonists. In: Egger CM, LoveL, Doherry T, eds. Pain management in veterinary practice', Ames, Iowa: Wiley Blackwell 2014, 93-103.

50. Selmi AL, Mendes GM, Lins BT, Figueiredo JP, Barbudo-Selmi GR. Evaluation of the sedative and cardiorespiratory effects of dexmedetomidine, dexmedetomidine-butorphanol, and dexmedetomidineketamine in cats', Journal of the American Veterinary Medical Association 2003;222(1):37-41.

51. Slingsby LS, Taylor PM. Thermal antinociception after dexmedetomidine administration in cats: a dosefinding study', J Vet Pharmacol Ther 2008;31(2):135142.

52. Talke PO, Traber DL, Richardson CA, Harper DD, Traber LD. The effect of $\alpha 2$ agonist-induced sedation and its reversal with an $\alpha 2$ antagonist on organ blood flow in sheep', Anesthesia and Analgesia 2000;90(5):1060-1066.

53. Uilenreef MJC, McKusick BC, Hellebrekers LJ. Dexmedetomidine continuous rate infusion during isoflurane anaesthesia in canine surgical patients', Veterinary Anaesthesia Analgesia 2008;35(2):141-153.

54. Valtolina C, Robben JH, Uilenreef J, Murrell JC, Aspegre'n J, McKusick BC, et al. Clinical evaluation of the efficacy and safety of a constant rate infusion of dexmedetomidine for postoperative pain management in dogs', Veterinary Anaesthesia and Analgesia 2009;36:369-383.

55. Yoshitomi O, Cho S, Hara T, Shibata I, Maekawa T, Ureshino $\mathrm{H}$, et al. Direct protective effects of dexmedetomidine against myocardial ischemiareperfusion injury in anesthetized pigs. Shock 2012;38(1):92-97. 